\title{
Avaliação da gestão em atenção básica em um município do interior de Minas Gerais
}

\author{
Virgínia Souza Santos, Giovanna Gaudenci Nardelli, Eliana Maria Gaudenci, Leila Aparecida \\ Kauchakje Pedrosa, Letícia Maria de Melo
}

\section{Resumo}

A Atenção Primária à Saúde (APS) possui o poder de organização para uma real mudança do modelo assistencial e esta assistência à saúde se apresenta nas Unidades Matriciais de Saúde (UMS), Unidades Básicas de Saúde (UBS), entre outros. A coordenação destas Unidades fica a cargo dos gerentes, cuja função administrativa é da mais alta importância, eles fazem com que a gerência se torne um instrumento importante para se efetivar políticas. Avaliar a qualidade do atendimento à população, da atenção primária a saúde na percepção dos profissionais das UBS. Trata-se de uma pesquisa de caráter descritivo, transversal e observacional, realizado com a utilização do método quantitativo, utilizando o $\mathrm{AMAQ}-\mathrm{AB}$, dimensão Gestão na $\mathrm{AB}$ como instrumento. $\mathrm{O}$ estudo realizou-se nas UBS e UMS localizadas na área urbana, no município de Uberaba-MG, após autorização da Secretaria Municipal de Saúde e Comissão de Ética em Pesquisas da Universidade Federal do Triângulo Mineiro (UFTM) sob o protocolo de número 2671. Como critérios de inclusão consideramos o tempo de no mínimo de 30 dias no atual cargo, e como exclusão, aqueles profissionais que estavam de férias, licença médica ou maternidade no momento da coleta de dados. Foram 34 participantes entre gerentes, enfermeiros e técnicos de enfermagem das UBS. Obtivemos a variação de idade entre 26 a 78 anos (sendo a média de 39 anos). A maioria dos profissionais são do sexo feminino $(88,2 \%)$, o estado civil prevalente foi o casado com $50 \%$. Na formação profissional o curso superior em enfermagem teve a porcentagem de $42,4 \%$ e o curso técnico em enfermagem obteve 39,4\%. Como nível de formação a especialização foi a mais encontrada $(45,5 \%)$ seguido de nível técnico $(39,4 \%)$. O tempo de experiência compreendeu-se de 1 a 27 anos (sendo a média de 10 anos). A carga horária com maior ocorrência foi 40 horas semanais com $78,8 \%$. Como cargo atual obtivemos $23,5 \%$ de gerentes das unidades, e 38,2\% para enfermeiros e $38,2 \%$ para técnicos de enfermagem. Como resultado final, realizando a média dos resultados das três subdimensões da dimensão Gestão em AB pudemos dizer que os participantes classificaram a dimensão, como Regular (pontuação 3), com resultado de 59,3\%. Conforme os resultados apresentados, é possível identificar que a gestão ainda não se encontra consolidada e assim, não podemos caracterizá-la como eficiente, o que exerce influências diretas na qualidade do serviço prestado a população e no processo de trabalho das estratégias de saúde da família. Os estudos trazem que reestabelecer ações pautadas em resultados avaliativos é um desafio, principalmente em virtude de que normalmente estes resultados demonstram as insatisfações e dificuldades relacionadas aos princípios e diretrizes do Sistema Único de Saúde (SUS) e da ABS, mas que devem ser continuamente perseguidos, tornando a avalição da melhoria do acesso e da qualidade da $\mathrm{AB}$ primordial e essencial.

Descritores: Atenção Primária de Saúde, Gestão da Atenção Básica, Profissionais de Saúde. 